\title{
Media Multitasking, Online Vigilance and Academic Performance among Students in three Southern African Countries
}

\author{
Daniel B. le Roux, Douglas A. Parry, Angelina Totolo, Gloria Iyawa, Jacques Holloway, \\ Andrew Prenter and Liam Botha \\ This is a preprint version of the article which is available at \\ https://doi.org/10.1016/j.compedu.2020.104056
}

\begin{abstract}
High levels of Internet-based media use is a defining feature of behaviour among university students. A growing body of evidence indicates, firstly, that their learning activities are characterised by frequent switching between academic content and online media, and, secondly, that this form of behaviour is negatively associated with academic outcomes. It is less clear, however, whether media use and media multitasking in general is associated with academic performance. In the present study we adopted an exploratory frame and a survey-based methodology to investigate this relationship among students from three countries in Southern Africa. In addition to self-reported media use measures, we investigated the predictive capacity of online vigilance on academic performance. Online vigilance is a novel construct which describes individual differences in users' cognitive orientation to online connectedness, their attention to and integration of online-related cues and stimuli, and their prioritisation of online communication. Our findings $(n=1445)$ indicate a weak, negative association between self-reported media use measures and academic performance, as well as online vigilance and academic performance. Combined, media use and online vigilance predict $9 \%$ of variance in academic performance for our full sample. However, when considering only Namibian students $(n=402)$, they predict $27 \%$ of variance. The study findings raise important questions relating to concerns over the potential impacts of general media use behaviours on academic performance among university students.

Keywords: Media use, Online vigilance, Academic performance, South Africa, Namibia,
\end{abstract}


Botswana

\section{Introduction}

Permanent online connectedness has emerged as one of the defining characteristics of life today (Vorderer et al., 2016; Vodanovich et al., 2010). While pervasive across generations, constant use of a wide variety of online media through multiple digital devices is particularly prevalent among adolescents (Cotten et al., 2011). This includes the current cohort of University students, who, in addition to having grown up in media saturated environments, generally enjoy easy access to the technological infrastructure that enable continuous engagement with online media (le Roux and Parry, 2017a). From an educational standpoint, it is difficult to overstate the value of access to online learning resources and the ever-growing collection of freely available educational content on the Internet (e.g., learning platforms, encyclopaedia, dictionaries, lectures, tutorials, Massive Open Online Courses, etc.). This is particularly true for students in developing countries where higher education sectors often lack the resources of those in the developed world.

While these positive effects are broadly acknowledged, a growing body of research has started to elucidate the potential downsides of chronic online media use for both learners and learning environments (Cotten et al., 2011; Junco, 2012; van der Schuur et al., 2015; le Roux and Parry, 2017a; Parry et al., 2019; Kirschner and De Bruyckere, 2017). A central theme in this domain is the manner in which online media frequently present as a distraction from academic work, introducing experiences of goal conflict among students (Van Koningsbruggen et al., 2017). Evidence suggests that, when confronted with these distractions, many students fail to self-regulate their media use patterns effectively (le Roux and Parry, 2019), and that this leads to the procrastination of academic work and enhanced anxiety (Sternberg et al., 2020). Such failure is exacerbated by the affordances of social media which encourage chronic monitoring of and responding to events in their users' online spheres.

To manage these conflicting goals, students often engage in media multitasking — a 
behavioural pattern in which attention is rapidly switched between media and non-media activities (Reinecke et al., 2018), or between multiple forms of media (Baumgartner et al., 2017). Extant evidence indicates that media multitasking in the context of learning activities interferes with attention and working memory, negatively affecting academic performance (May and Elder, 2018). To counter these effects, interventions which promote abstinence from off-task media use during lectures and study sessions have been proposed (Berry and Westfall, 2015; Katz and Lambert, 2016; Parry et al., 2019; Parry and le Roux, 2019). While such interventions may prove beneficial, they do not address the potential impacts, if any, of general media use and media multitasking (i.e., outside of learning contexts) on students' cognitive orientation and functioning, or their academic performance. Despite a growing number of studies in this domain (see Liu et al., 2017, for a review), there remains a lack of consensus on whether and how the behaviours and cognitive patterns associated with permanent online connectedness interact with academic performance among university students.

In the present study we aim to advance knowledge in this domain in three ways. Firstly, unlike the bulk of earlier studies that consider media use and multitasking in the context of academic work, we consider the association between general media use behaviours (including multitasking) and academic performance. Secondly, we adopt the notion of online vigilance, as proposed by Reinecke et al. (2018), to investigate students' psychological (as opposed to technological) connectedness to their online spheres and its association with academic performance. And, thirdly, we conduct our investigation based on data collected from students in three countries in Southern Africa - South Africa, Botswana and Namibia. With the exception of a very small subset of studies, the evidence in this domain results from studies performed in the US, Europe or Asia.

We commence by reviewing current evidence and outlining theoretical perspectives that explain the potential interaction between these constructs. Thereafter we present our research questions, methodology and results. 


\section{Literature Review}

\subsection{Media Use, Media Multitasking and Academic Performance}

Multitasking describes the purposeful, concurrent performance of independent tasks, each associated with distinct intentions (Salvucci and Taatgen, 2015). Media multitasking, by extension, describes a form of multitasking in which one or more of the concurrently performed tasks involve engagement with digital media. While some scholars limit media multitasking to only describe concurrent media activities (e.g., Baumgartner et al., 2017), others have adopted broader conceptualisations which also include concurrently performed media and non-media activities (e.g., Reinecke et al., 2018). The human ability to perform tasks concurrently creates the false impression that we are able to process, on a cognitive level, multiple streams of stimuli in parallel (Ophir et al., 2009; Kahneman, 1973; Loh and Kanai, 2015; Gazzaley and Rosen, 2016; Kirschner and De Bruyckere, 2017). In reality however, we rely on a range of cognitive functions that allow us to rapidly switch between stimuli streams (Salvucci et al., 2009; Liu et al., 2017). While many adolescents believe that they are able to multitask effectively (le Roux and Parry, 2017a), "it has been broadly shown that rapid switching behaviour, when compared to carrying out tasks serially, leads to poorer learning results in students and poorer performance of the tasks being carried out" (Kirschner and De Bruyckere, 2017, p. 139). Accordingly, frequent multitasking should not be equated with effective multitasking.

Among university student populations, the prevalence of multitasking has been shown both in general and academic settings. Deng et al. (2019), in their analysis of students' smartphone use, found that a majority of usage is characterised by rapid switching between platforms/applications. Judd (2013), in an investigation of self-directed study sessions in a computer laboratory, found that multitasking occurred in more than $70 \%$ of sessions observed.

Three primary arguments underpin the proposition that media use/multitasking is associated with academic performance among university students. The first proposes that high 
levels of media use displace time which could be spent on academic work, leading to lower performance outcomes (van der Schuur et al., 2015). The second proposes that learning activities that are punctuated by frequent instances of non-academic (or off-task) media use instances will involve cognitive costs and impede the processing and encoding of information into long term memory (Oulasvirta and Saariluoma, 2004). The third suggests that chronic media multitasking can, over time, weaken the ability to sustain attention (Ophir et al., 2009; Gazzaley and Rosen, 2016; Ralph et al., 2014) and, by extension, negatively impact academic performance.

Based on their review of 43 studies examining media use in relation to academic performance, van der Schuur et al. (2015) report that "the majority of the studies show that media use during academic activities is negatively related to the three aspects of academic performance" - academic outcomes, study-related attitudes and behaviours, and perceived academic learning. Across all the reviewed studies the correlations, while negative, were small to medium in magnitude, with larger effect sizes shown in experimental studies. The same pattern emerges based on a later review by le Roux and Parry (2017b) which considers 35 studies investigating the relationship between media multitasking and academic performance. The authors find that, across both correlational and experimental studies, only four of the 35 studies did not find significant negative association between the two variables.

Interpretation of these findings should be conducted with consideration of the distinction between a general pattern of media use and media use during learning activities (e.g., lectures and study sessions) specifically. Wu et al. (2018), for example, found that cyberloafing in class is negatively associated with academic performance, but that the association is positive when cyberloafing is performed in moderation outside class. Liu et al. (2017), in a meta-analysis of the relationship between general use of social network sites and academic performance, found a small negative association. Measures of media multitasking, like those proposed by Ophir et al. (2009) and Baumgartner et al. (2017), do not distinguish between contexts. In principle, however, deficits in academic performance that result from multitasking in learning 
contexts can be explained by the cognitive costs of switching between on-task and off-task content. It is less clear, however, whether (and how) general media multitasking would be associated with academic performance. In a rare study of this association, Cain et al. (2016) found that general media multitasking among $8^{\text {th }}$ grade students $(n=74)$ is negatively associated with standardised achievement tests of Math $(r=-.30)$ and English Language Arts $(r=-.29)$.

\subsection{Online Vigilance and Academic Performance}

Reinecke et al. (2018) propose that our continuous interactions with the affordances of online platforms trigger processes of instrumental and attentional learning that, over time, cultivate online vigilance. The construct describes individual differences in users' cognitive orientation to online connectedness, their attention to and integration of online-related cues and stimuli, and their prioritisation of online communication (Reinecke et al., 2018). Individuals that "are high in online vigilance will think more often and more intensively about their personal online sphere even when they are not using their mobile devices" (Reinecke et al., 2018, p. 2). An important property of the construct is that it facilitates distinction between technological connectedness and psychological connectedness, suggesting that some users may develop higher degrees of online vigilance than others despite comparable media

use patterns. While acknowledging conceptual overlap, Reinecke et al. (2018) distinguish online vigilance from Internet or technology addiction (Griffiths et al., 2016; Kuss et al., 2014, 2017; Petry et al., 2014; Abendroth et al., 2020), arguing that it represents "a much more mundane form of involvement with the online environment that does not necessarily impair individual functioning and mental health" (Reinecke et al., 2018, p. 7).

The distinction between technological and psychological connectedness provides a novel lens for the investigation of the relationship between media use and academic performance. While the weight of current evidence indicates that off-task media use during learning activities negatively affects performance due to the cognitive costs of switching (Ophir et al., 2009; May and Elder, 2018), online vigilance directs our attention to the manner in which 
users' online spheres consume their cognitive resources at times when they are not engaging with media. This suggests that, while content switching costs can be eliminated by abstaining from media use while studying, those that are highly vigilant of their online spheres may experience great difficulty in psychologically disconnecting from online content which, in turn, may impact their academic performance.

Extant evidence suggests that online vigilance is positively associated with internet multitasking, mind-wandering and fear of missing out, and negatively associated with affective well-being and mindfulness, all among samples primarily consisting of younger individuals (Johannes et al., 2018; Schneider and Hitzfeld, 2019; Reinecke et al., 2018). However, no studies have, as of yet, investigated the relationship between online vigilance and academic performance or other task-related outcomes.

\subsection{Media Use and Academic Performance among Students in Southern Africa}

Despite its status as a developing country, South Africa has a high mobile phone penetration rate, particularly among students. The country has a population of just under 60 million (World Bank, 2020), and an Internet penetration rate of 56.17\% (International Telecommunication Union, 2020). It also has a fairly well developed higher education sector with two universities ranked inside the top 200, and seven inside the top 500 of the Times Higher Education World Rankings (Times Higer Education, 2020). Overall, close to one million students are enrolled at public higher education institutions in South Africa (Statistics South Africa, 2020). Over a decade ago, Kreutzer (2009) already found extensive mobile device use among low-income students, with $83 \%$ accessing mobile Internet applications on a daily basis. North et al. (2014), five years later, reported that only 1\% of students did not own a mobile phone, or had not owned one recently. The relationship between media use and academic performance has also been studied within South African student populations. Leysens et al. (2016) considered the use of various forms of media (instant messaging, social media, microblogs, search engines, and encyclopaedia) by university students $(n=192)$ during lectures and found a negative correlation between overall in-lecture media use and 
self-reported academic performance $(r=-0.22)$. In a later study, le Roux and Parry (2017a) $(n=1678)$ confirm this relationship $(r=-0.07)$, but find no association between general media use and academic performance.

Namibia, with a population of only 2.5 million (World Bank, 2020) and an Internet penetration rate of $51 \%$ (International Telecommunication Union, 2020), has three universities and a wide variety of higher education institutions (United Nations Education, Scientific and Cultural Organization, 2020), but does not currently have any universities in the overall Times Higher Education World University Rankings (Times Higer Education, 2020). Tertiary education enrolment in Namibia has increased from 46963 in 2014 to 59208 in 2018, with 71.8\% of enrolments in the public sector (Namibia Council for Higher Education, 2018). Asino (2015) found that $99 \%$ of Namibian students have access to a mobile phone, and that $58 \%$ of students used social media daily via their mobile phones. Additionally, it was found that more than $80 \%$ of Namibian students had access to a computer. De Kock (2018), in a study of Facebook use among first year university students in Namibia $(n=559)$, found that almost 90\% have Facebook accounts and half of them report using the platform at least once every few days. However, they rarely used it during lectures and only $8 \%$ of participants reported experiencing problems associated with the compulsive use of Facebook. A majority of participants $(72 \%)$ reported that they never or rarely experienced academic impairment due to their Facebook use and no relationship between either self-reported intensive or compulsive Facebook use and academic performance (as measured by grade average) was found. Mwilima and Hangula (2017) found that 56\% of Namibian students believe their phones made a positive contribution to their academic performance if used responsibly, but $34 \%$ of students believe they are a distraction that negatively impacts academic performance. Dhaka and Naris (2019) adopt the Internet Addiction Test proposed by Young (2010) to determine levels of 'Internet addiction' among Namibian students $(n=100)$. Their findings indicate that $38 \%$ of students experience low levels of Internet addiction, while $57 \%$ and $5 \%$ experience moderate and severe levels of Internet addiction respectively. These findings, 
however, should be interpreted with care considering the broad range of concerns relating to the conceptualisation and measurement of Internet addiction (Abendroth et al., 2020).

Botswana has a population of just over 2.2 million (World Bank, 2020) and an Internet penetration rate of 47\% (International Telecommunication Union, 2020). Though the country has numerous higher education institutions (Botswana Ministry of Tertiary Education, Research, Science and Technology, 2020), it does not currently have any universities in the overall Times Higher Education World University Rankings (Times Higer Education, 2020). Overall tertiary education enrolment in Botswana has increased from 47889 in 2008 to 53 450 in 2018 (Human Resource Development Council of Botswana, 2018). Asino (2015) found that, like their Namibian counterparts, $99 \%$ of students in Botswana owned a mobile phone and more than $80 \%$ of students indicated they had access to either a laptop or desktop computer at their home. Tsholetso et al. (2017), adopting a survey methodology $(n=390)$, found that they spent more time using social media than studying. A majority of their respondents not only believed that the use of social media did not affect their academic activities, but felt that it benefits their academic performance. Results of their quantitative analysis, however, indicate a negative association between the amount of time students report spending on social media daily and academic performance. The authors argue that, while the technological infrastructure provided by the relevant university expanded students' access to web-based learning resources and enriched the quality of academic offering, the absence of restrictions and controls over social media use meant that many students failed to regulate their media use effectively. In a qualitative study of students in Botswana $(n=100)$, Mooketsi and Mutshewa (2019) investigate the gratification of social needs through the use of social media platforms. Data from semi-structured interviews indicate, firstly, that a majority of students experience high degrees of attachment to their mobile devices, and that "the thought of being without their mobile phones made them distressed" (p. 134). They also found most students were prepared to interrupt whatever they were doing to respond to events in their online spheres. 


\subsection{Research Problem and Questions}

As outlined in the preceding sections, extant evidence indicates that rapid switching between learning activities and off-task media during academic activities like lectures and study sessions is associated with reduced academic performance. However, the role of students' media use patterns outside of academic settings is less clear. Some studies have found small negative association between social media use and academic performance, while others found no relationship. Additionally, there is a lack of evidence about the relationship between general media multitasking (i.e., outside academic contexts) and academic performance. Acknowledging these findings and adopting an exploratory stance, we posed the following research question:

RQ1: Does general media use and media multitasking behaviour predict variance in academic performance among students in South Africa, Botswana and Namibia?

Additionally, considering the premise proposed by Reinecke et al. (2018) that some students may, through continuous engagement with online media, develop high degrees of online vigilance, we pose a second research question:

RQ2: Does general media use and media multitasking behaviour predict variance in online vigilance among students in South Africa, Botswana and Namibia?

Thirdly, to investigate whether students' online vigilance predicts variance in their academic performance in addition to their general media use behaviours, we pose a third question:

RQ3: Does online vigilance predict variance in academic performance among students in South Africa, Botswana and Namibia over and above that predicted by general media use and media multitasking behaviour? 


\section{Materials and Methods}

To address our research questions we conducted an exploratory, survey-based study involving participants from three countries in Southern Africa. In the sections which follow we outline our sampling procedure and study variables.

\subsection{Participants}

We targeted student samples at three public, Southern African universities, one in South Africa, one in Botswana, and one in Namibia. Of the three universities targeted, the South African one is the largest with a total of just over 30000 students. The Namibian university has just over 11000 enrolled students in total, while the one in Botswana has around 16 000. To recruit respondents email invitations to complete the survey on an online survey platform (Checkbox) were sent to all undergraduate students at each of the three institutions. In total, 1476 responses to the survey were received, from which 30 were removed due to incompleteness. The final sample consisted of $n=1445$ undergraduate students $(58.16 \%$ female). Data collection was conducted in South Africa in the fourth quarter of 2019, and in Botswana and Namibia in the first quarter of 2020 (prior to any social distancing or lock-down procedures due to COVID-19).

\subsection{Study Variables}

To assess media multitasking we used the Media Multitasking Index-Short (MMI-S; Baumgartner et al. (2017)), which considers multitasking across three primary activities (watching TV, using social media, and sending messages via phone or computer) and four secondary activities (the three primary activities and listening to music). To include a broader range of video-related media, we changed the 'watching TV' to 'video watching'. Respondents indicated on a Likert scale from 1 (not at all) to 6 (3 hours or more) their use-duration on an average day for each of the primary activities. For each of the secondary items respondents indicate, on a Likert scale from 1 (never) to 4 (very often), how frequently 
they engage simultaneously with each of the primary items. To calculate the MMI-S these values were combined using the formula proposed by Ophir et al. (2009).

Respondents were asked to indicate their gender (male, female or other) and year of birth. Self-reported daily smartphone use was measured using a single item with a Likert scale ranging from 1 (Less than 30 minutes) to 9 (More than 4 hours).

Academic performance was assessed using a single item. Respondents were asked to indicate what their average performance is in their courses or modules. Options ranged from less than $40 \%$ to more than $85 \%$ with $5 \%$ intervals. The phrasing of the item and the response options were designed in consultation with academic staff members at each of the three institutions where data was collected.

Online Vigilance was assessed with the Online Vigilance Scale (Reinecke et al., 2018). It consists of three subscales — salience, monitoring, and reactivity - and 12 items are presented. Responses are provided through Likert scales ranging from 1 (Does not apply at all) to 5 (Fully applies). The salience subscale concerns cognitive orientation (e.g., "I constantly monitor what is happening online" and "I have a hard time disengaging mentally from online content"). The monitoring subscale concerns chronic monitoring of online content and messages (e.g., "I constantly monitor what is happening online" and "I always keep an eye on what is happening online at the moment"). The reacting subscale concerns immediate responsiveness to online messages (e.g., "When I receive an online message I immediately give it my full attention" and "When I receive an online message it triggers an impulse in me to check it right away"). To calculate a respondent's online vigilance responses to all 12 items were averaged. Reinecke et al. (2018) provide evidence indicating that the online vigilance scale demonstrates a stable factor structure across various contexts and populations.

\subsection{Ethical Considerations}

Ethical clearance for the study and permission to distribute survey-invitations were obtained from the relevant institutional bodies. All participants indicated informed consent to the study purpose, methods, analysis and reporting approach, before voluntarily completing 
Table 1: Descriptive statistics for study variables by country and overall.

\begin{tabular}{lccccccccc}
\hline & \multicolumn{2}{c}{ Botswana } & \multicolumn{2}{c}{ Namibia } & \multicolumn{2}{c}{ South Africa } & \multicolumn{2}{c}{ Overall } \\
\cline { 2 - 10 }$n$ & \multicolumn{2}{c}{139} & \multicolumn{2}{c}{402} & & & & & \multicolumn{2}{c}{1445} \\
\hline Variable & Mean & SD & Mean & SD & Mean & SD & Mean & SD \\
\hline Daily smartphone use $^{\mathrm{a}}$ & 7.10 & 2.33 & 6.44 & 1.37 & 6.24 & 2.18 & 6.33 & 2.03 \\
Video $^{\mathrm{b}}$ & 4.12 & 1.54 & 3.32 & 0.91 & 3.68 & 1.37 & 3.62 & 1.30 \\
Messaging $^{\mathrm{b}}$ & 3.76 & 1.71 & 3.87 & 1.20 & 4.15 & 1.37 & 4.04 & 1.37 \\
Social mediab $_{\text {Media multitasking }}$ & 4.51 & 1.48 & 3.43 & 1.03 & 3.85 & 1.42 & 3.80 & 1.36 \\
Online vigilance $_{\text {Academic performance }}^{\mathrm{c}}$ & $\mathbf{1 . 6 7}$ & 0.71 & 1.24 & 0.66 & 1.53 & 0.67 & 1.47 & 0.69 \\
\hline
\end{tabular}

${ }^{\text {a }}$ Less than 30 minutes $=1 ; 30-60$ minutes $=2 ; 1 \mathrm{~h}-1 \mathrm{~h} 30 \mathrm{~min}=3 ; 1 \mathrm{~h} 30 \mathrm{~min}-2 \mathrm{~h}=4$; $2 \mathrm{~h}-2 \mathrm{~h} 30 \mathrm{~min}=5 ; 2 \mathrm{~h} 30 \mathrm{~min}-3 \mathrm{~h}=6$; $3 \mathrm{~h}-3 \mathrm{~h} 30 \mathrm{~min}=7$; $3 \mathrm{~h} 30 \mathrm{~min}-4 \mathrm{~h}=8$; more than $4 \mathrm{~h}=9$.

b Not at all $=1$; less than 30 minutes $=2 ; 30$ minutes to 1 hour $=3 ; 1$ to 2 hours $=4$; 2 to 3 hours $=5 ; 3$ hours or more $=6$.

${ }^{c}$ Less than $40 \%=1 ; 40-45 \%=2 ; 45-50 \%=3 ; 50-55 \%=4 ; 55-60 \%=5 ; 60-65 \%=6 ; 65-$ $70 \%=7 ; 70-75 \%=8 ; 75-80 \%=9 ; 80-85 \%=10 ;$ more than $85 \%=11$.

the survey at a time and place of their own choosing.

\section{Results}

Table 1 presents the sample sizes of each country, as well as descriptive statistics for our study variables (by country and overall). For the full sample, students reported using their smartphones, on average, between 150 and 210 minutes per day, with students in Botswana indicating the highest daily average (between 180-240 minutes). Only 14 respondents (0.98\%) indicated that they did not own a smartphone. Overall, most time was reported to be spent on instant messaging (60-120 minutes), with social media and video watching being the second and third most used forms of media. Students in Botswana indicated higher levels of media multitasking than their peers in Namibia and South Africa, while South African students reported the highest levels of online vigilance.

Due to the relatively large differences in the sample sizes (Total: $n=1445$; Botswana: $n=139,9.68 \%$; Namibia: $n=402,27.80 \%$; South Africa: $n=904,62.52 \%$ ), care should be 
Table 2: Results of ANOVAs (Type III Sums of Squares) indicating the effect of country, and pairwise comparisons between the three samples.

\begin{tabular}{lrrrrrrrr}
\hline Variable & $F$ & $d f$ & $p$ & $\eta_{p}^{2}$ & $90 \%$ CI & SA-BOT $^{\mathrm{a}}$ & BOT-NAM $^{\mathrm{b}}$ & SA-NAM $^{\mathrm{S}}$ \\
\hline Daily smartphone use & 15.35 & 2,1442 & $<.001$ & .02 & {$[.01, .03]$} & $p<.001$ & $p<.001$ & $p=.823$ \\
Video watching & 22.55 & 2,1442 & $<.001$ & .03 & {$[.02, .05]$} & $p=.002$ & $p<.001$ & $p<.001$ \\
Messaging & 9.39 & 2,1442 & $<.001$ & .01 & {$[.00, .02]$} & $p=.020$ & $p=.474$ & $p<.001$ \\
Social media & 35.68 & 2,1442 & $<.001$ & .05 & {$[.03, .07]$} & $p<.001$ & $p<.001$ & $p<.001$ \\
Media multitasking & 33.22 & 2,1442 & $<.001$ & .04 & {$[.03, .06]$} & $p=.032$ & $p<.001$ & $p<.001$ \\
Online vigilance & 8.13 & 2,1442 & $<.001$ & .01 & {$[.00, .02]$} & $p=.392$ & $p=.306$ & $p<.001$ \\
Academic performance & 31.10 & 2,1442 & $<.001$ & .04 & {$[.03, .06]$} & $p<.001$ & $p<.001$ & $p=.017$ \\
\hline
\end{tabular}

${ }^{a}$ Holm-adjusted significance values of pairwise comparison between South Africa and Botswana.

${ }^{\mathrm{b}}$ Holm-adjusted significance values of pairwise comparison between Botswana and Namibia.

${ }^{\mathrm{c}}$ Holm-adjusted significance values of pairwise comparison between South Africa and Namibia.

taken when comparing measures of central tendency and dispersion of variables by country. For each of the variables we conducted an ANOVA (with Type III Sums of Squares to account for subgroup sample size differences) to determine whether the observed differences between countries were statistically significant. The results are presented in Table 2. Overall, with effect sizes ranging from $\eta_{p}^{2}=.01$ to $\eta_{p}^{2}=.05$ the magnitude of these differences is small. The largest effect of country was shown for social media use $\left(\eta_{p}^{2}=.05,90 \%\right.$ CI $\left.[.03, .07]\right)$.

Figure 1 depicts the numeric properties and distribution of the media multitasking index-short for the full sample and per country. The South African sample, due to its relatively large sample size, approximates the overall distribution more closely than that of the two other countries. Notably, the distributions in Botswana $(M=1.67, S D=0.71)$ and South Africa $(M=1.53, S D=0.67)$ are less skewed than that of Namibia $(M=1.24, S D=$ $0.66)$.

Figure 2 depicts the numeric properties and distribution of online vigilance and its subcomponents for the full sample (panel A) and for participants from each country considered (panel B). The plots indicate the medians, interquartile ranges, minimums, maximums and outliers, with the distributions shown as density plots. For the full sample, reactibility is slightly higher than monitoring and salience, which is explained by the higher level of reactibility among South African students. Considering Panel B, the plots indicate that distribution in the Namibia sample is more concentrated, with salience as the highest sub- 


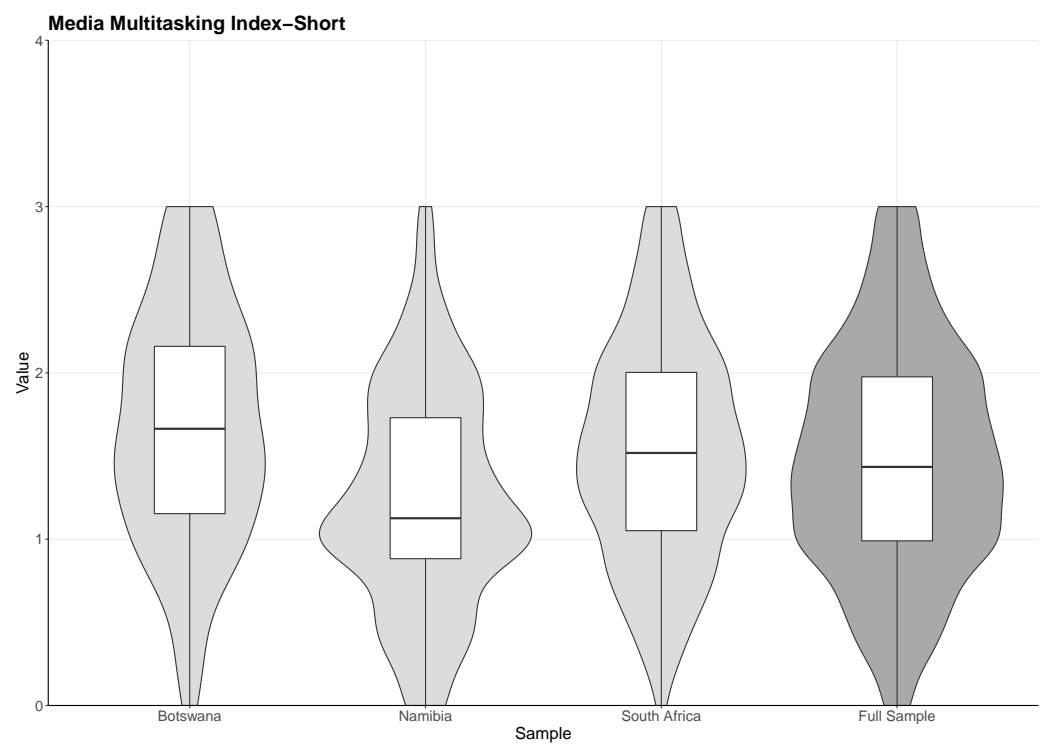

Figure 1: Distribution of media multitasking overall and per country.

component. In both Botswana and South Africa, reactibility is the highest sub-component.

Table 3 presents zero-order bivariate correlations (Spearman's $\rho$ ) between the variables for the full sample. For all correlations we applied the Holm-Bonferroni adjustment for multiple tests. With the exception of a small number of correlations in the Botswana sample, we found positive associations between all media use variables, including online vigilance. In the full sample the strongest of these is between reported daily smartphone use and social media use $(\rho=.55, p<.001)$. However, across all correlations the effects are small to moderate, negating concerns about the effect of multicollinearity in further analyses. In the full sample, all self-reported media use variables are negatively associated with academic performance. The same pattern is observable for the Namibia and South Africa samples. In the Botswana sample, however, only reported instant messaging duration is associated with academic performance, and the direction is positive $(\rho=.28, p<.05)$.

While a small negative association between the media multitasking index and academic performance was found in the full sample $(\rho=-.14, p<.001)$, no association was found in the Botswana sample. In the Namibia sample this association was stronger $(\rho=-.33, p<$ 

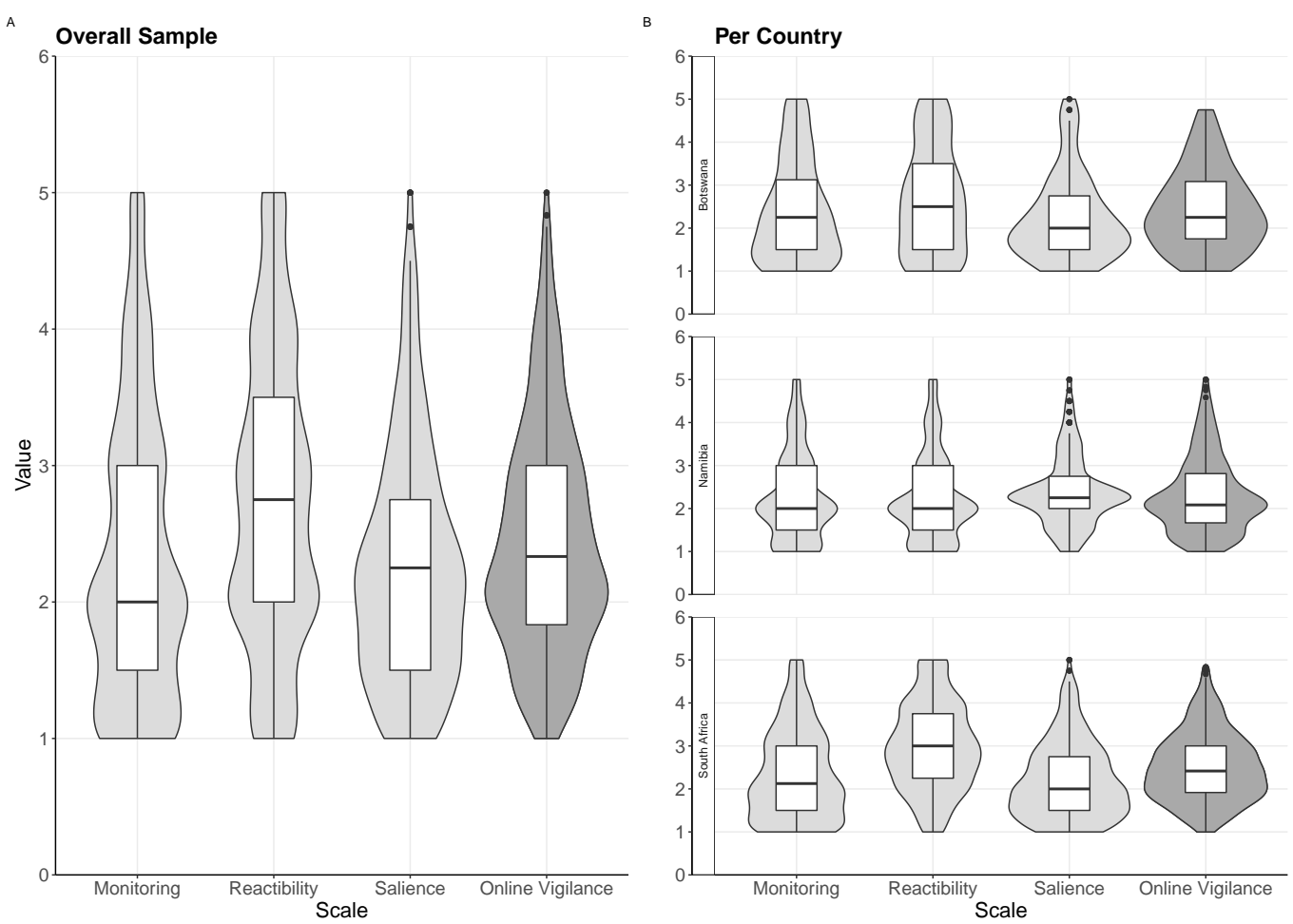

Figure 2: Distribution of overall online vigilance and sub components for the full sample (panel A) and individual countries (panel B).

.001). The same pattern is observable for the association between online vigilance and academic performance. A small association was found in the full sample $(\rho=-.17, p<.001)$, with no association in the South Africa and Botswana samples. However, in the Namibia sample this association was moderate $(\rho=-.51, p<.001)$. Due to these differences a decision was made to address RQ1 and RQ3 both overall and separately for South Africa and Namibia. Due to the small size of its sample, we did not include Botswana in these second analyses.

\subsection{Media use behaviours as predictors of academic performance}

Our first research question concerned the predictive capacity of self-reported general media use behaviours over academic performance for the full sample. Despite small countrylevel differences $\left(\eta_{p}^{2}=.04,90 \%\right.$ CI $\left.[.03, .06]\right)$, academic performance was approximately symmetrical (skewness $=.02$, kurtosis $=-.41$ ), with a median category of $60-65 \%$. To address the research question, for the full sample, we conducted a multiple linear regression 
Table 3: Zero-order bivariate correlations between study variables.

\begin{tabular}{lrrrrrr}
\hline Sample & DSU & VW & MES & SM & MMT & OV \\
\hline Full sample $(n=1445)$ & & & & & & \\
& & & & & & \\
Video watching & $0.36^{* * *}$ & & & & & \\
Messaging & $0.52^{* * *}$ & $0.19^{* * *}$ & & & & \\
Social media & $0.55^{* * *}$ & $0.27^{* * *}$ & $0.53^{* * *}$ & & & \\
Media multitasking & $0.42^{* * *}$ & $0.29^{* * *}$ & $0.46^{* * *}$ & $0.53^{* * *}$ & & \\
Online vigilance & $0.29^{* * *}$ & $0.14^{* * *}$ & $0.19^{* * *}$ & $0.32^{* * *}$ & $0.39^{* * *}$ & \\
Academic performance & $-0.10^{* * *}$ & $-0.07^{*}$ & -0.05 & $-0.07^{*}$ & $-0.14^{* * *}$ & $-0.17^{* * *}$ \\
\hline Botswana $(n=139)$ & & & & & & \\
& & & & & & \\
Video watching & $0.29^{* *}$ & & & & & \\
Messaging & $0.36^{* * *}$ & 0.15 & & & & \\
Social media & $0.52^{* * *}$ & 0.16 & $0.44^{* * *}$ & & & \\
Media multitasking & $0.38^{* * *}$ & $0.29^{* *}$ & $0.54^{* * *}$ & $0.42^{* * *}$ & & \\
Online vigilance & $0.33^{* *}$ & 0.15 & 0.13 & $0.49^{* * *}$ & $0.35^{* * *}$ & \\
Academic performance & 0.12 & 0.05 & $0.28^{* *}$ & 0.16 & 0.10 & -0.14 \\
\hline
\end{tabular}

Namibia $(n=402)$

Video watching $\quad 0.20^{* * *}$

Messaging $\quad 0.41^{* * *} \quad 0.17^{* *}$

Social media $\quad 0.32^{* * *} 0.32^{* * *} \quad 0.51^{* * *}$

Media multitasking $\quad 0.41^{* * *} \quad 0.38^{* * *} \quad 0.46^{* * *} \quad 0.48^{* * *}$

Online vigilance $\quad 0.36^{* * *} \quad 0.26^{* * *} \quad 0.12^{*} \quad 0.31^{* * *}$

$\begin{array}{lllllll}\text { Academic performance } & -0.20^{* * *} & -0.22^{* * *} & -0.09 & -0.24^{* * *} & -0.33^{* * *} & -0.51^{* * *}\end{array}$

South Africa $(n=904)$

Video watching

Messaging

Social media

Media multitasking

Online vigilance

Academic performance

$$
0.40^{* * *}
$$

$0.61^{* * *} \quad 0.22^{* * *}$

$0.60^{* * *} \quad 0.24^{* * *} \quad 0.57^{* * *}$

$0.43^{* * *} \quad 0.25^{* * *} \quad 0.45^{* * *}$

$0.28^{* * *}$

$0.09^{*}$

$0.21^{* * *}$

$0.52^{* * *}$

$0.28^{* * *}$

$-0.10^{*}-0.08^{*}$ $-0.04$

Note. DSU = Daily smartphone use; VW = Video watching; MES = Messaging;

$\mathrm{SM}=$ Social media $; \mathrm{MMT}=$ Media multitasking; $\mathrm{OV}=$ Online vigilance.

${ }^{* * *} p<0.001,{ }^{* *} p<0.01,{ }^{*} p<0.05$ 
Table 4: Results of multiple linear regression predicting academic performance with self-reported media use behaviours while controlling for country.

\begin{tabular}{lrrrrr}
\hline Variable & $B$ & $\mathrm{SE}$ & $\beta$ & $t$ & $95 \% \mathrm{CI}$ \\
\hline Daily smartphone use & -0.07 & 0.03 & -0.08 & $-2.33^{*}$ & {$[-0.12,-0.01]$} \\
Video watching & -0.07 & 0.04 & -0.05 & -1.75 & {$[-0.14,0.00]$} \\
Messaging & 0.12 & 0.04 & 0.10 & $2.79^{* *}$ & {$[0.04,0.21]$} \\
Social media & -0.04 & 0.05 & -0.03 & -0.83 & {$[-0.13,0.05]$} \\
Media multitasking & -0.41 & 0.08 & -0.16 & $-4.93^{* * *}$ & {$[-0.60,-0.25]$} \\
\hline $\mathrm{R}^{2}$ & 0.08 & & & & \\
adj. $\mathrm{R}^{2}$ & 0.08 & & & \\
F Statistic & $18.31^{* * *}(\mathrm{df}=7 ; 1437)$ & & \\
\hline
\end{tabular}

Note. $N=1445$. $B$ represents unstandardised regression coefficients; SE represents the standard error of $B ; \beta$ represents standardised regression coefficients. ${ }^{* * *} p<0.001,{ }^{* *} p<0.01,{ }^{*} p<0.05$

controlling for country and predicting academic performance with reported daily smartphone use, video watching, messaging, social media, and media multitasking. Table 4 presents the results of this regression. Overall, the model predicts $8 \%$ of variance in academic performance $\left(R^{2}=.08 ; F(7 ; 1437)=18.31, p<.001\right)$, with media multitasking as the strongest predictor $(\beta=-.16, p<.001)$. The second strongest predictor is instant messaging which has a positive effect on academic performance $(\beta=.13, p<.001)$. Neither reported video watching nor social media use were significant predictors of academic performance in the model.

To address RQ1 for South Africa and Namibia separately, we conducted, with each country's sample, a multiple linear regression to predict academic performance with daily smartphone use, video watching, messaging, social media, media multitasking. In the South Africa sample the model predicts a small amount of variance in academic performance $\left(R^{2}=\right.$ $.03 ; F(5 ; 898)=6.51, p<.001)$. The variance explained by the model in the Namibia sample is higher $\left(R^{2}=.15 ; F(5 ; 396)=13.54, p<.001\right)$. We tested the statistical significance of the difference in $R^{2}$ between the two countries using bootstrapping procedures to compute an interval estimate using the $95 \%$ BCa bootstrap confidence interval with 5000 resamples for each country. We found there to be no overlap in 95\% CIs for $R^{2}$ between the South 
Table 5: Results of multiple linear regression predicting online vigilance with media use behaviours.

\begin{tabular}{lrrrrr}
\hline Variable & $B$ & $\mathrm{SE}$ & $\beta$ & $t$ & $95 \%$ CI \\
\hline Daily smartphone use & 0.07 & 0.01 & 0.017 & $5.33^{* * *}$ & {$[0.04,0.09]$} \\
Video watching & -0.02 & 0.02 & -0.04 & -1.454 & {$[-0.06,0.01]$} \\
Messaging & -0.07 & 0.02 & -0.11 & $-3.56^{* * *}$ & {$[-0.10,-0.03]$} \\
Social media & 0.08 & 0.02 & 0.13 & $4.01^{* * *}$ & {$[0.04,0.12]$} \\
Media multitasking & 0.38 & 0.04 & 0.31 & $10.44^{* * *}$ & {$[0.31,0.45]$} \\
\hline $\mathrm{R}^{2}$ & 0.19 & & & \\
adj. R & 0.19 & & & \\
F Statistic & $48.17^{* * *}(\mathrm{df}=7 ; 1437)$ & & \\
\hline
\end{tabular}

Note. $N=1445 . B$ represents unstandardised regression coefficients; SE represents the standard error of $B ; \beta$ represents standardised regression coefficients. ${ }^{* * *} p<0.001,{ }^{* *} p<0.01,{ }^{*} p<0.05$

Africa sample $[.013, .057]$ and the Namibia sample $[.071, .207]$, confirming the statistical significance of the difference.

\subsection{Media use behaviours as predictors of online vigilance}

To address our second research question we determined whether general media use and media multitasking behaviour predict variance in online vigilance among students in our sample. To address this question we conducted a multiple linear regression to predict online vigilance with daily smartphone use, video watching, messaging, social media, and media multitasking as factors while controlling for country. The results of the regression are presented in Table 5. Combined, the five media use behaviour variables explained $19 \%$ of the variance in online vigilance $\left(R^{2}=.19 ; F(7 ; 1437)=48.17, p<.001\right)$. With the exception of video watching $(\beta=-.04, p=.14)$, all the media use behaviours predicted online vigilance. Of these, media multitasking $(\beta=.31, p<.01)$ was the strongest predictor, while instant messaging was the only significant predictor with a negative effect $(\beta=-.11, p<.001)$.

\subsection{Media use behaviours and online vigilance as predictors of academic performance}

Our final research question concerned the predictive capacity of general media use behaviours combined with online vigilance over academic performance. To address the research 
Table 6: Results of multiple linear regression predicting academic performance with media use behaviours, country and online vigilance.

\begin{tabular}{lrrrrr}
\hline Variable & $B$ & $\mathrm{SE}$ & $\beta$ & $t$ & $95 \% \mathrm{CI}$ \\
\hline Daily smartphone use & -0.05 & 0.03 & -0.04 & -1.72 & {$[-0.10,0.02]$} \\
Video watching & -0.07 & 0.04 & -0.06 & -1.93 & {$[-0.12,0.03]$} \\
Messaging & 0.10 & 0.04 & 0.08 & $2.39^{*}$ & {$[-0.04,0.13]$} \\
Social media & -0.02 & 0.05 & -0.03 & -0.38 & {$[-0.06,0.12]$} \\
Media multitasking & -0.31 & 0.09 & -0.12 & $-3.64^{* * *}$ & {$[-0.42,-0.08]$} \\
Online vigilance & -0.38 & 0.06 & -0.33 & $-4.35^{* * *}$ & {$[-0.43,-0.19]$} \\
\hline $\mathrm{R}^{2}$ & 0.09 & & & & \\
adj. R & 0.09 & & & \\
F Statistic & $18.59^{* * *}(\mathrm{df}=8 ; 1436)$ & & \\
\hline
\end{tabular}

Note. $N=1445$. $B$ represents unstandardised regression coefficients; $\mathrm{SE}$ represents the standard error of $B ; \beta$ represents standardised regression coefficients.

${ }^{* * *} p<0.001,{ }^{* *} p<0.01,{ }^{*} p<0.05$

question, we adapted our model to include online vigilance in addition to the media use behaviour variables used in the model used to address RQ1, while continuing to control for country. The results of the regression are presented in Table 6. Overall, the model explains $9 \%$ of variance in academic performance $\left(R^{2}=.09 ; F(8 ; 1436)=18.59, p<.001\right)$, with online vigilance $(\beta=-0.33, p<.001)$ and media multitasking $(\beta=-0.12, p<.001)$ as the strongest negative predictors. As was found for RQ1, instant messaging is also a positive predictor in this model $(\beta=.08, p<.05)$.

Comparison of the models used in RQs 1 and 3 indicated that the addition of online vigilance as predictor increased the explained variance in academic performance from $8 \%$ to $9 \%$. While statistically significant $\left(\Delta R^{2}=.02, p<.001\right)$, the small change in variance explained indicates that, over and above the media use variables used as predictors for RQ1, online vigilance provides negligible explanatory power over academic performance.

To address RQ3 for South Africa and Namibia separately, we conducted, with each country's sample, a multiple linear regression to predict academic performance with daily smartphone use, video watching, messaging, social media, media multitasking and online vigilance. In the South Africa sample the model predicts $4 \%$ of variance in academic perfor- 
mance $\left(R^{2}=.04 ; F(6 ; 897)=5.44, p<.001\right)$. The variance explained by the model in the Namibia sample is substantially higher $\left(R^{2}=.27 ; F(6 ; 395)=24.52, p<.001\right)$. We tested the statistical significance of the difference in $R^{2}$ between the two countries using bootstrapping procedures to compute an interval estimate using the $95 \% \mathrm{BCa}$ bootstrap confidence interval with 5000 resamples for each country. No overlap in 95\% CIs for $R^{2}$ between the South Africa sample $[.013, .056]$ and the Namibia sample $[.172, .345]$ was found.

To gain further insight into the relationship between academic performance and online vigilance among Namibian students, we analysed the correlations between academic performance and the three subscales of the online vigilance scale. We found significant correlations between each of the subscales and academic performance, with negligible differences between their magnitudes (monitoring: $r=-0.48, p<.001$, salience: $r=-0.42, p<.001$, reacting: $r=-0.47, p<.001)$.

\section{Discussion}

The present study investigated the association between media use behaviours and academic performance through surveys distributed among university students in three Southern African countries - Botswana, Namibia and South Africa. The study addressed three primary research questions relating, firstly, to the predictive capacity of general media use behaviours over academic performance; secondly, to the predictive capacity of general media use behaviours over online vigilance - a novel construct which describes individuals' cognitive orientation to online connectedness, their attention to and integration of online-related cues and stimuli, and their prioritisation of online communication (Reinecke et al., 2018); and thirdly, the combined predictive capacity of media use behaviours and online vigilance over academic performance.

Our findings indicate that, across the three populations where data were collected, small differences exist in the media use behaviours considered. While the South African higher education sector is much more developed than those of its northerly neighbours, our 
findings suggest that students at these institutions engage with Internet-based media at similar frequencies and volumes. Thus, while there may be many differences between their educational experiences, they are all characterised by high levels of Internet-based media use. Moreover, in terms of hours of daily smartphone use, the students in our sample behave in a similar way to students in the US as found by Deng et al. (2019).

When considering the association between reported media use behaviours and academic performance, our findings align with those of earlier studies in this domain (Liu et al., 2017), indicating a small, negative association. Importantly, we do not propose that this association is causal in nature, nor do our cross-sectional data enable us to single out a particular interpretation of this finding. We argue, consequently, that the association may occur due to the displacement of time that could be spent on academic work (van der Schuur et al., 2015), reduced learning performance due to task-switching (Oulasvirta and Saariluoma, 2004), weakened ability to sustain attention (Ophir et al., 2009; Gazzaley and Rosen, 2016; Ralph et al., 2014), or any combination of these or other factors unaccounted for in the present study. We note, however, that the relative strength of media multitasking as predictor in our model (see Table 4), suggests that frequent, rapid switching between media is a more important factor in academic outcomes than volume or frequency of media use alone.

In accordance with Reinecke et al. (2018)'s premise that online vigilance is acquired through processes of instrumental and attentional training that occur during media use, our findings indicate that reported media use behaviours are positively associated with online vigilance. However, two factors should be considered when interpreting this finding. Firstly, when combined, all the media use behaviours we tested for, including media multitasking, predicted only $19 \%$ of the variance in online vigilance for our full sample. This suggests that an individual's degree of psychological connectedness to their online sphere is determined by (a potentially wide range of) factors in addition to their behaviour with media. What these factors are remains open for debate, but, as Reinecke et al. (2018) acknowledge, 
personal characteristics which determine need satisfaction through media engagement will play a role by impacting processes of attentional and instrumental training. Secondly, while processes of attentional and instrumental training provide an intuitive causal mechanism for the relationship between media use and online vigilance, our data do not permit causal conclusions.

Our third research question concerned the role of online vigilance in predicting academic performance over and above media use behaviours. As shown in Table 6, the updated model provides only a $1 \%$ increase in explanatory power. Consideration of the standardised coefficients indicates that online vigilance is a stronger predictor of academic performance when controlling for media use behaviours. This, combined with the increased predictive capacity of the model, indicate that the association between media use and academic performance is partially mediated by online vigilance. However, both the small effect size of the model and the negligible increase in predictive capacity suggest that, in terms of association with academic performance in the full sample, the distinction between technological and psychological connectedness provides little explanatory value.

Acknowledging these findings for our full sample, the substantial differences in these effects observed between the South African and Namibian samples requires some elaboration. In the South African sample, only $4 \%$ of variance in academic performance could be predicted by media use and online vigilance, for the Namibian sample this effect is $27 \%$. Interpretation of this difference presents a challenge as it does not align with previous findings among Namibian students as reported by De Kock (2018). It may relate to the distribution of data representing media multitasking and online vigilance which, as illustrated in Figures 1 and 2, are more concentrated for Namibian students. Alternatively, it is conceivable that institutional factors not accounted for may be confounding the association. le Roux and Parry (2017b), for example, found significant differences between subject areas when considering the associations between media use patterns and academic performance, arguing that factors like teaching and assessment styles may play a role. Finally, we acknowledge 
the possibility that such confounding factors may be of a cultural rather than institutional nature. We propose that future studies investigate these possibilities by, firstly, conducting qualitative studies to form a more textured understanding of media use patterns among Namibian students and, secondly, analysing the association between media use and academic performance across multiple Namibian institutions.

The findings of the present study raise important questions relating to concerns over the potential impacts of general media use behaviours on academic performance among university students. Like previous studies in this domain, our findings indicate that, across the three populations considered, the observed effect size is small (given conventional interpretations of effect sizes). Moreover, this effect remains small when the role of psychological connectedness to online content is considered in addition to reported media engagement, explaining $9 \%$ of variance in academic performance. A key question is whether this effect is strong enough to raise concern among educators or prompt interventions to curb media engagement among students.

To address this question we acknowledge, in accordance with Funder and Ozer (2019), that a small effect size may, under certain circumstances, be consequential and should not be ignored off-hand. To aid interpretation of the effects we observed, it is instructive to benchmark them against the effects of other factors on academic performance. For example, Credé et al. (2010), in a meta-analysis of studies $(k=33)$ on the effect of class attendance on academic performance find a correlation of $\rho=.41$, arguing that it is the best known predictor of college grades. Noftle and Robins (2007), in a meta-analysis of studies ( $k=$ 20) of personality and academic outcomes in college, find the following pooled effect sizes: extraversion $(r=-.04)$, agreeableness $(r=.09)$ conscientiousness $(r=.26)$, neuroticism $(r=-.07)$, and openness $(r=.05)$. Lastly, a meta-analysis of demographic variables and academic performance by Richardson et al. (2012) shows small effects for socioeconomic background $(r=.11)$, age $(r=.08)$, and gender $(r=.09)$; as well as medium effects for measures of high school GPA $(r=.40)$, SAT $(r=.29)$, ACT scores $(r=.40)$, and 
general intelligence $(r=.20)$. Hence, when expressed in terms of the proportion of variance explained $\left(R^{2}\right)$, the effects of general media multitasking $(2 \%)$ and online vigilance $(3 \%)$ are larger than that of socioeconomic background (1\%), but smaller than the strongest personality predictor (conscientiousness [7\%]) and class attendance (17\%). The combined effect of media use behaviour and online vigilance (while controlling for country) on academic performance $(9 \%)$ is comparable to that of conscientiousness and SAT scores.

Finally, we briefly acknowledge a number of important limitations of our study. Firstly, it has been shown that self-reports of media use tend to correlate poorly with actual use data (Andrews et al., 2015). Accordingly, our use of self-report measures of media use limits the accuracy of our data and, potentially, the validity of our results. Future research using logbased measures of media use should be conducted among our target population to address this limitation. This is also applicable to, though less problematic, in the case of academic performance. In their meta-analysis of the validity of self-reported grade point averages, Kuncel et al. (2005) observe a correlation of $(r=.9)$ between self-reported and actual grades among college students $(n=12089)$. The authors argue that "although systematic biases appear to influence (sometimes strongly) the validity of self-reported grades and grade point averages, it should be kept in mind that self- reported grades generally predict outcomes to a similar extent as actual grades" (Kuncel et al., 2005, p. 76). Secondly, the cross-sectional nature of our data does not permit us to draw causal conclusions about the associations we identified. To address this limitation, in addition to using log-based tracking of media use, subsequent studies can, for instance, use longitudinal designs and make use of cross-lagged panel models to unpack the associations between general media use and academic performance over time. Thirdly, the effects of the differences in the sizes of our three samples must be acknowledged. Specifically, the relatively large size of the South African sample implies that South African students are over-represented in the full sample. Fourthly, our use of convenience sampling to obtain respondents implies that our sample is not necessarily representative of the three population(s) targeted. Finally, our data does not provide adequate 
texture to draw meaningful conclusions about the notable differences observed between the South African and Namibian samples. For this, in addition to more targeted quantitative research, we recommend that further qualitative work be conducted to generate possible explanations and hypotheses to be tested.

\section{Conclusion}

In conclusion, it should be acknowledged that, while our evidence indicates that the general use of Internet-based media may not be particularly harmful to university students' academic performance, it also suggests that, at an aggregate level, it provides little or no benefit. This is perhaps particularly important considering that our targeted populations reside in developing countries where, one may argue, access to Internet-based media has the most potential to enhance performance in higher education. Additional research is required to investigate the specific applications, media, and websites engaged with and, on this basis, understand potential academic implications. When contextualising our findings against those of the reviewed studies of media use among students in Southern Africa, it seems that the Internet is primarily used to satisfy needs of a social or entertainment nature.

Our study did not consider the use of Internet-based academic resources specifically and, one may argue, that the inclusion of variables which represent such use may, in future studies, provide different insights.

\section{Declaration of Interest}

The author(s) declare that there are no conflicts of interest with respect to the authorship or the publication of this article.

This research did not receive any specific grant from funding agencies in the public, commercial, or not-for-profit sectors. 


\section{References}

Abendroth, A., Parry, D.A., le Roux, D.B., Gundlach, J., 2020. An analysis of problematic media use and technology use addiction scales-what are they actually assessing? .

Andrews, S., Ellis, D.A., Shaw, H., Piwek, L., 2015. Beyond Self-Report: Tools to Compare Estimated and Real-World Smartphone Use. PLOS ONE 10, e0139004. doi:10.1371/ journal.pone. 0139004 .

Asino, T., 2015. Factors that Influence the Diffusion Process of Mobile Devices in Higher Education in Botswana and Namibia. Doctoral dissertation. The Pennsylvania State University.

Baumgartner, S.E., Lemmens, J.S., Weeda, W.D., Huizinga, M., 2017. Measuring Media Multitasking: Development of a Short Measure of Media Multitasking for Adolescents. Journal of Media Psychology 29, 92 - 101.

Berry, M.J., Westfall, A., 2015. Dial d for distraction: The making and breaking of cell phone policies in the college classroom. College Teaching 63, 62-71.

Botswana Ministry of Tertiary Education, Research, Science and Technology, 2020. Areas of responsibility. Data retrieved from Ministry of Tertiary Education, Research, Science and Technology, https://www.gov.bw/ministries/ ministry-tertiary-education-research-science-and-technology.

Cain, M.S., Leonard, J.A., Gabrieli, J.D.E., Finn, A.S., 2016. Media multitasking in adolescence. Psychonomic Bulletin \& Review 23, 1932-1941. doi:10.3758/s13423-016-1036-3.

Cotten, S.R., McCullough, B., Adams, R., 2011. Technological influences on social ties across the lifespan, in: Fingerman, K.L., Berg, Cynthia, A., Smith, J., Antonucci, Toni, C. (Eds.), Handbook of Life-Span Development. Springer Publishing Company. chapter 25, pp. 647-671. 
Credé, M., Roch, S.G., Kieszczynka, U.M., 2010. Class attendance in college: A metaanalytic review of the relationship of class attendance with grades and student characteristics. Review of Educational Research 80, 272-295. doi:10.3102/0034654310362998.

De Kock, I., 2018. Relating Intensive and Compulsive Facebook Use With Life Satisfaction and Academic Performance amongst First Year University of Namibia Students. Ph.D. thesis. University of Namibia.

Deng, T., Kanthawala, S., Meng, J., Peng, W., Kononova, A., Hao, Q., Zhang, Q., David, P., 2019. Measuring smartphone usage and task switching with log tracking and self-reports. Mobile Media \& Communication 7, 3-23. doi:10.1177/2050157918761491.

Dhaka, P., Naris, C., 2019. A Study of the Correlation Between Internet Addiction and Aggressive Behaviour Among the Namibian University Students, in: Lecture Notes on Data Engeneering and Communication Technologies: Aata Science and Big Data Analytics. Springer. chapter 1, pp. 1-9. doi:10.1007/978-981-10-7641-1_1.

Funder, D.C., Ozer, D.J., 2019. Evaluating effect size in psychological research: Sense and nonsense. Advances in Methods and Practices in Psychological Science 2, 156-168. doi:10.1177/2515245919847202.

Gazzaley, A., Rosen, L.D., 2016. The Distracted Mind. June, MIT Press, Cambridge, MA.

Griffiths, M.D., Van Rooij, A.J., Kardefelt-Winther, D., Starcevic, V., Király, O., Pallesen, S., Müller, K., Dreier, M., Carras, M., Prause, N., Others, 2016. Working towards an international consensus on criteria for assessing Internet gaming disorder: A critical commentary on Petry et al.(2014). Addiction 111, 167-175.

Human Resource Development Council of Botswana, 2018. Tertiary education statistics for botswana. 
International Telecommunication Union, 2020. Ict price baskets. Data retrieved from the International Telecommunication Union (ITU), https://www.itu .int/net4/ITU-D/ipb/ index.html.

Johannes, N., Veling, H., Dora, J., Meier, A., Reinecke, L., Buijzen, M., 2018. MindWandering and Mindfulness as Mediators of the Relationship Between Online Vigilance and Well-Being. CyberPsychology, Behavior \& Social Networking 00.

Judd, T., 2013. Making sense of multitasking: Key behaviours. Computers \& Education 63, 358-367. doi:10.1016/j. compedu.2012.12.017.

Junco, R., 2012. Too much face and not enough books: The relationship between multiple indices of Facebook use and academic performance. Computers in Human Behavior 28, 187-198. doi:10.1016/j.chb.2011.08.026.

Kahneman, D., 1973. Attention and effort. Prentice-Hall, Englewood Cliffs, $\{$ NJ\}.

Katz, L., Lambert, W., 2016. A happy and engaged class without cell phones? it's easier than you think. Teaching of Psychology 43, 340-345.

Kirschner, P.A., De Bruyckere, P., 2017. The myths of the digital native and the multitasker. Teaching and Teacher Education 67,135-142. doi:10.1016/j.tate.2017.06.001.

Kreutzer, T., 2009. Internet and Online Media Usage on Mobile Phones among Low-Income Urban Youth in Cape Town, in: Pre-conference workshop at the International Communication Association (ICA) Conference, pp. 1-21.

Kuncel, N.R., Credé, M., Thomas, L.L., 2005. The validity of self-reported grade point averages, class ranks, and test scores: A meta-analysis and review of the literature. Review of educational research $75,63-82$.

Kuss, D., Griffiths, M., Karila, L., Billieux, J., 2014. Internet addiction: A systematic 
review of epidemiological research for the last decade. Current pharmaceutical design 20, $4026-4052$.

Kuss, D., Griffiths, M.D., Pontes, H.M., 2017. Chaos and confusion in DSM-5 diagnosis of Internet Gaming Disorder: Issues, concerns, and recommendations for clarity in the field. Journal of Behavioral Addictions 6, 103-109.

Leysens, J.L., Le Roux, D., Parry, D., 2016. Can I have your attention, please? An empirical investigation of media multitasking during university lectures, in: ACM International Conference Proceeding Series. doi:10.1145/2987491.2987498.

Liu, D., Kirschner, P.A., Karpinski, A.C., 2017. A meta-analysis of the relationship of academic performance and Social Network Site use among adolescents and young adults. Computers in Human Behavior 77, 148-157. doi:10.1016/j.chb.2017.08.039.

Loh, K.K., Kanai, R., 2015. How Has the Internet Reshaped Human Cognition? The Neuroscientist, 1073858415595005.

May, K.E., Elder, A.D., 2018. Efficient, helpful, or distracting? A literature review of media multitasking in relation to academic performance. International Journal of Educational Technology in Higher Education 15. doi:10.1186/s41239-018-0096-z.

Mooketsi, B.E., Mutshewa, A., 2019. An exploratory investigation of students' use of social networking sites and their individual and social needs: A case study of the University of Botswana undergraduates. African Journal of Library Archives and Information Science $29,131-141$.

Mwilima, F., Hangula, V., 2017. The Effects of Cell Phone Use on Academic Performance in Tertiary Education. International Journal of Law, Humanities \& Social Science 1, 33-38.

Namibia Council for Higher Education, 2018. 2018 Namibia Council for Higher Education Statistical Yearbook (NHESY). 
Noftle, E.E., Robins, R.W., 2007. Personality Predictors of Academic Outcomes: Big Five Correlates of GPA and SAT Scores. Journal of Personality and Social Psychology 93, 116-130. doi:10.1037/0022-3514.93.1.116.

North, D., Johnston, K., Ophoff, J., 2014. The Use of Mobile Phones by South African University Students. Issues in Informing Science and Information Technology 11, 115138.

Ophir, E., Nass, C., Wagner, A.D., 2009. Cognitive control in media multitaskers. Proceedings of the National Academy of Sciences 106, 15583-15587.

Oulasvirta, A., Saariluoma, P., 2004. Long-term working memory and interrupting messages in human-computer interaction. Behaviour \& Information Technology 23, 53-64.

Parry, D.A., le Roux, D.B., 2019. Media multitasking and cognitive control: A systematic review of interventions. Computers in Human Behavior 92, 316-327.

Parry, D.A., le Roux, D.B., Cornelissen, L.A., 2019. Managing in-lecture media use: the feasibility and value of a split-class policy. Journal of Computing in Higher Education doi:10.1007/s12528-019-09232-z.

Petry, N.M., Rehbein, F., Gentile, D.A., Lemmens, J.S., Rumpf, H.J., Mößle, T., Bischof, G., Tao, R., Fung, D.S.S., Borges, G., Others, 2014. An international consensus for assessing internet gaming disorder using the new DSM-5 approach. Addiction 109, 1399-1406.

Ralph, B.C.W., Thomson, D.R., Cheyne, J.A., Smilek, D., 2014. Media multitasking and failures of attention in everyday life. Psychological Research 78, 661-669. doi:10.1007/ s00426-013-0523-7.

Reinecke, L., Klimmt, C., Meier, A., Reich, S., Hefner, D., Knop-Huelss, K., Rieger, D., Vorderer, P., 2018. Permanently online and permanently connected: Development and validation of the Online Vigilance Scale. PloS one 13. 
Richardson, M., Abraham, C., Bond, R., 2012. Psychological correlates of university students' academic performance: a systematic review and meta-analysis. Psychological bulletin $138,353$.

le Roux, D.B., Parry, D.A., 2017a. A New Generation of Students: Digital Media in Academic Contexts, in: 46th Annual Conference of the Southern African Computer Lecturers' Association, SACLA 2017, Springer, Magaliesburg.

le Roux, D.B., Parry, D.A., 2017b. In-lecture media use and academic performance: Does subject area matter? Computers in Human Behavior 77, 86-94. doi:10.1016/j.chb. 2017.08 .030 .

le Roux, D.B., Parry, D.A., 2019. Off-task media use in academic settings: cycles of selfregulation failure. Journal of American College Health , 1-8doi:10.1080/07448481.2019. 1656636.

Salvucci, D.D., Taatgen, N.A., 2015. The Multitasking Mind. Aging 7, 956-963. arXiv:arXiv:1011.1669v3.

Salvucci, D.D., Taatgen, N.a., Borst, J., 2009. Toward a unified theory of the multitasking continuum: From concurrent performance to task switching, interruption, and resumption, in: Proceedings of the SIGCHI Conference on Human Factors in Computing Systems, CHI'09, Boston, MA. pp. 1819-1828. doi:10.1145/1518701.1518981.

Schneider, F.M., Hitzfeld, S., 2019. I Ought to Put Down That Phone but I Phub Nevertheless: Examining the Predictors of Phubbing Behavior. Social Science Computer Review doi:10.1177/0894439319882365.

van der Schuur, W., Baumgartner, S.E., Sumter, S.R., Valkenburg, P.M., 2015. The consequences of media multitasking for youth: A review. Computers in Human Behavior 53, 204-215. doi:10.1016/j.chb.2015.06.035. 
Statistics South Africa, 2020. Education Series Volume VI: Education and Labour Market Outcomes in South Africa, 2018.

Sternberg, N., Luria, R., Chandhok, S., Vickers, B., Kross, E., Sheppes, G., 2020. When facebook and finals collide-procrastinatory social media usage predicts enhanced anxiety. Computers in Human Behavior , 106358.

Times Higer Education, 2020. World university rankings. Data retrieved from the Times Higher Education World University Rankings), https://www.timeshighereducation. com/world-university-rankings.

Tsholetso, T., Maunganidze, L., Faimau, G., 2017. Online Social Networking and Academic Performance at the University of Botswana. Mosenodi Journal 20, 4-15. doi:10.1017/ CB09781107415324.004.

United Nations Education, Scientific and Cultural Organization, 2020. Tvet, higher education and innovation policy review, namibia. Data retrieved from UNESCO Digitla Library, https://unesdoc. unesco.org/ark:/48223/pf0000245818.

Van Koningsbruggen, G.M., Hartmann, T., Du, J., 2017. Always on? explicating impulsive influences on media use, in: Permanently online, permanently connected. Routledge, pp. $65-74$.

Vodanovich, S., Sundaram, D., Myers, M., 2010. Research commentary — digital natives and ubiquitous information systems. Information Systems Research 21, 711-723.

Vorderer, P., Krömer, N., Schneider, F.M., 2016. Permanently online - Permanently connected: Explorations into university students' use of social media and mobile smart devices. Computers in Human Behavior 63, 694-703. doi:10.1016/j.chb.2016.05.085.

World Bank, 2020. Data for south africa, namibia, botswana. Data retrieved from World Development Indicators, https://data. worldbank.org/?locations=ZA-NA-BW. 
Wu, J., Mei, W., Ugrin, J.C., 2018. Student Cyberloafing in and out of the Classroom in China and the Relationship with Student Performance. Cyberpsychology, Behavior, and Social Networking 21, 199-204. doi:10.1089/cyber.2017.0397.

Young, K., 2010. Clinical assessment of Internet addictedclients, in: Young, K., De Abreau, N. (Eds.), Internet addiction: A handbook and guide for evaluation and treatment. Wiley, New York, pp. 19-34. 